\title{
Introduction to Traffic Calming Measures \& Analysing the Level of Service of an Urban Street: A Stakeholder Survey
}

\author{
Sanchi Rewar, Anirudh Mathur, Prachi Kushwaha
}

Department of Civil Engineering, Swami Keshvanand Institute of Technology, Management \& Gramothan, Jaipur302017 (INDIA)

Email: sanchichoudhary9@gmail.com, anirudh.mathur@skit.ac.in,Prachi.kushwaha@skit.ac.in Received 30.06.2021, received in revised form 2.08.2021, accepted 2.08.2021 doi: $10.47904 / I J S K I T .11 .2 .2021 .11-15$

\begin{abstract}
With increasing number of road accidents, there arises a demand for the measures and techniques that would help in reducing the occurrence and fatalities of such accidents. The term Traffic Calming is relatively new to India and presents itself as a promising strategy to curb the increasing number of road accidents. The present study is about the various measures that can be adopted to attain the objective of fewer road mishaps. For this, a Stakeholder Survey was conducted on Mahal Road, Jagatpura, Jaipur to understand the issues related to the increase in traffic volume over the past few years. Results show that the increase in traffic volume on Mahal Road is attributed to the infrastructural development in the region owing to commercialization of the area in the recent years. Moreover, Mahal Road lacks the availability of public transport and utilities like pedestrian facilities and cycle tracks. Finally, some conclusions are drawn from the survey results and recommendations made for improving the road users experience.
\end{abstract}

Keywords- Traffic Calming Measures, Pedestrians, NonMotorised Vehicles

\section{INTRODUCTION}

India is an augmenting country, currently with a population of 1.32 billion and is expected to witness an increase in its population by $25 \%$ with reference to 2011 and will reach a figure of 1.52 billion by 2036 [1]; this population boom undoubtedly led to an increase in the use of vehicles. Without proper transportation facilities it becomes cumbersome to fulfil our daily needs. With use of a greater number of vehicles, it also becomes imperative to consider the safety of people travelling through roads. Today, one of the major concerns all over the world is road safety. According to the Hindustan Times report [2] "in 2019 more than 1 lakh 51 thousand people were killed in 4 lakh 80 thousand road accidents, wherein Delhi grabbed the first position with 1,463 deaths followed by Jaipur $(1,283)$ ". To reduce the number of road accidents, road-based 'Traffic Calming Measures' have been adopted and are proven to be successful in various parts of the World. The concept of Traffic Calming came into existence back in 1960 when a significant increase in car use and car ownership emerged majorly in the western part of the World. The two main problems which became evident were 'Congestion' and 'Queuing' and in order to avoid long queues drivers preferred taking shortcuts in between from local streets disturbing the residents with higher volume of road traffic. In 1968 a replacement approach appeared within the Netherlands. An urban planner with the help of some local residents reconstructed a street in the city of Delft to calm the traffic. The basic principle was to merge road users, so that private cars will have to reduce their speed [3]. The basic principle of Traffic Calming is to reduce the vehicle speeds so that there is a reduction in rate of accidents, pollution etc., and vehicles travelling at speeds below $30 \mathrm{kmph}$ can move on road along with pedestrians with relative safety [9].

\section{LITERATURE REVIEW}

In recent years the number of deaths and serious injuries has increased in India. According to the report submitted by the World Bank (2021), nearly "1.5 lakh lives gets lost in about 4.5 lakh road accidents per annum which bring India to hold nearly 11 percent of total death rates all around the World. In the year 2019 World Bank reported, the cost involved in such injuries estimates about 7.5 percent of GDP" [4]. Traffic Calming Measures are typically designed to keep the traffic moving, albeit at a slower speed, which mitigates most of the "negatives of traffic control" as described in Manual on Uniform Traffic Control Devices [5]. Holler [6] further classified these into two groups- to control the speed of traffic or to control the volume.

Classification of 'Traffic Calming Measures' is illustrated in Table 1.

To resolve mis-happenings due to road accidents, one of the measures such as 'Area Widening' can be implemented to reduce road traffic injuries. Specific changes in the road layout can be done by road widening, implementation of one-way streets, creation of road junctions etc. But more evaluations are required along with road widening to get the desired results [7].

According to A. Vaitkus et al. [8] high speed is amongst the other factors that are responsible for road accidents. If somehow a reduction in the speed of the vehicle could be accomplished, the ratio of accidents would also decrease. Gateways should be used as self-explaining road concept elements at the entrance 
of settlements or urban areas. To reduce the speed of the vehicles he suggested including measures such as 'Vertical Deflections' coupled with 'Horizontal Deflection' to bring about a greater overall effect. Various 'Traffic Calming Measures' such as 'Road narrowing', design of 'Speed humps and bumps', 'Roundabouts' etc. could be used to revise the dissenting effects of vehicles, and to improve the situation for non-motorized transport [9]. Due to improper rules and designs, pedestrians and fastmoving vehicles share the same space on the roads. Apart from this, encroachments are being used by people for trading purposes which causes congestion [10].

A study was conducted in Cambridge, Massachusetts on the midblock locations and intersections to evaluate the waiting time of pedestrian crossings in the crosswalks. Some of the measures like raised intersections and refuse islands helped in increasing the percentage of pedestrians. TCM would help the pedestrians to enjoy a safer road experience and simultaneously helping in reducing the speed of the vehicle. Although it needs to be stated that the measures also do not give assurance the vehicles would reduce their speed.

Apart from this, a safety-based analysis using collision records should be conducted [11].TCM are self-enforcing and usually do not require complex traffic control devices which will also reduce the cost involved in accidents. A difference can also be seen in the traffic condition in India versus other developed countries [9]. A few of them are listed below:

- In India, two-wheelers, four-wheelers and nonmotorised vehicles can be seen sharing an equal space.

- No tractors and non-motorised vehicles are seen in other developed countries whereas in India these are seen on the same road.

- In India, horizontal deflections would work better whereas, in other developed countries where two-wheelers are not a major issue, vertical deflections will give better results.

- Another issue which can be seen in India is that a very little segregation of traffic can be seen i.e., all the types of modes use the same road whereas in other countries there are separate lanes designed for each mode.

Apparently not major work on 'Traffic Calming 'has been done in India, several studies have investigated the effects of TCM on prevention of road accidents in foreign countries, the current study involved use of stakeholder survey done on Mahal Road, Jaipur, India as a tool to identify the difficulties and problems faced by the people. The results of stakeholder survey can be beneficial in planning a traffic calming plan/measure for the area under study.

Table 1 Classification of 'Traffic Calming Measures' [12, 13]

\begin{tabular}{|c|c|c|c|}
\hline VOLUME CONTROL & SPEED CONTROL & & \\
\hline $\begin{array}{ll} & \text { Full road closure } \\
- & \text { Half road closures } \\
- & \text { Diagonal road closures } \\
\text { - } & \text { Modified 'T' intersection } \\
\text { - } & \text { Left in / Left out island }\end{array}$ & $\begin{array}{ll}\text { Vertical deflections } \\
\text { - } & \text { Road humps } \\
\text { - } & \text { Raised tables } \\
\text { - } & \text { Raised Crosswalks } \\
\text { - } & \text { Road cushions } \\
\text { - } & \text { Thumps } \\
\text { - } & \text { Mechanical Humps } \\
\text { - } & \text { Rumble Strips }\end{array}$ & $\begin{array}{cl}\text { Horizontal deflections } \\
\bullet \quad \text { Kerb Extensions } \\
-\quad \text { Road Narrowing } \\
-\quad \text { Chicanes } \\
\bullet \quad \text { Roundabouts } \\
-\quad \text { On street Parking } \\
\quad \text { Management }\end{array}$ & $\begin{array}{l}\text { Lane Marking and } \\
\text { Signage } \\
\text { - } \quad \text { Speed limit signs } \\
\text { - } \quad \text { One-way signs } \\
\text { - } \quad \text { Gtop signs } \\
\text { - } \quad \text { "Zebra" crossings }\end{array}$ \\
\hline
\end{tabular}

\section{DATA COLLECTION AND SURVEY}

\subsection{Site selection}

The stretch selected for this study was from Jagatpura flyover to Ramchandrapura turn, near Bombay Hospital, Jaipur, also known as Mahal Road. The total length of the stretch is $6 \mathrm{~km}$. The increasing trend of office and commercial space in Jaipur, especially in Jagatpura, has led to city's primary industrial growth and currently it is one of the fastestgrowing suburbs in Jaipur.

Back in 2011-2013 there were hardly any shops or markets but from 2015 onwards the market has grown tremendously with various new shops and farmer markets mushrooming in the region. Due to the opening of market and commercial space the traffic flow has also increased as a result people find Jagatpura route more convenient to travel to Pratap Nagar rather than going via Tonk Road. Fig 1 and Fig
2 shows the google image of Mahal Road and irregular movement of traffic on an intersection on Mahal Road respectively.

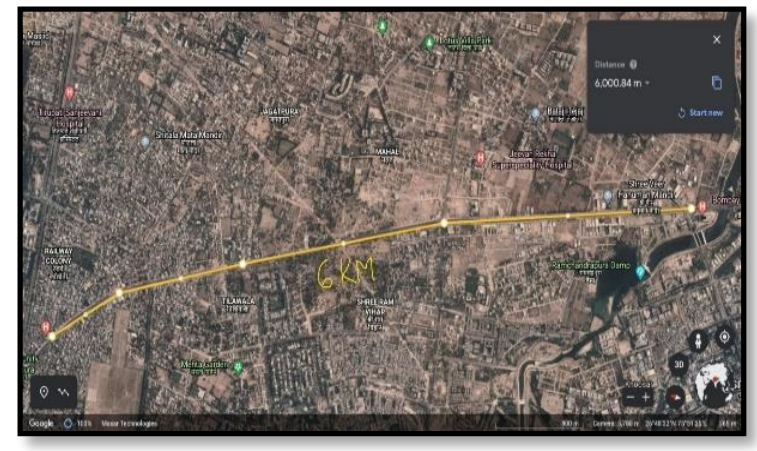

Fig. 1 Google image of Mahal Road (from Jagatpura flyover to Ramchandrapura turn, Jaipur) 


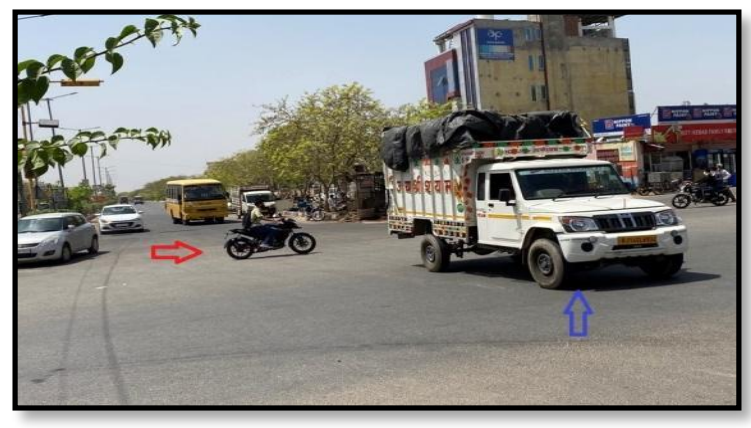

Fig. 2 Irregular movement of traffic on an intersection on Mahal Road.

\subsection{Survey}

The current study primarily focusses on the safety provided to pedestrians and NMT users, hence in order to identify the issues which were being faced by the people using the road and by local residents, a survey was planned to be conducted which focussed on the following points-

- The type and nature of the problem being faced by the people.

- Area where congestion occurs frequently.

- Possibility of land acquisition.

- Availability of resources.

- Facilities to the users etc.

A Stakeholder survey form (as shown in Annexure I) was created online and circulated to the nearby residents and road users using the Mahal Road regularly. Offline entries were also obtained to understand the onsite challenges being faced by the people.

\section{RESULTS AND ANALYSIS}

The results of the stakeholder survey are illustrated in the following figures.

$>$ Profile of respondents: A total of 208 responses were collected, out of which $75 \%$ accounts for the people between 18-35 years of age. Survey targeted heterogenous audience, regardless of which 104 responses had been submitted by employed persons, and about $42.3 \%$ by students.

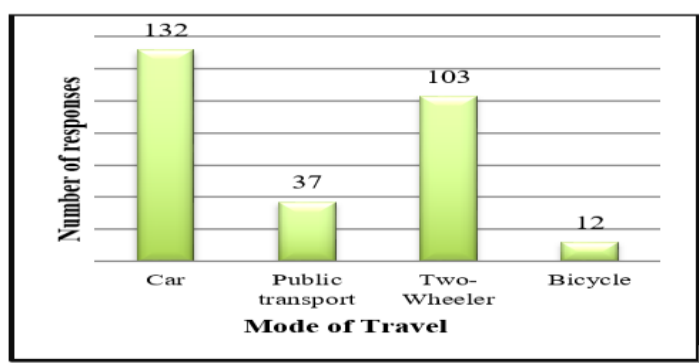

Fig. 3 Preferred mode of travel

$>$ Out of the responses that were obtained; majority of the people stated that they (132) prefer to travel by car i.e. $63.5 \%$ followed by two-wheelers (103) that is $49.2 \%$ and public transport (37) that is $17.8 \%$ as indicated in Fig 3.

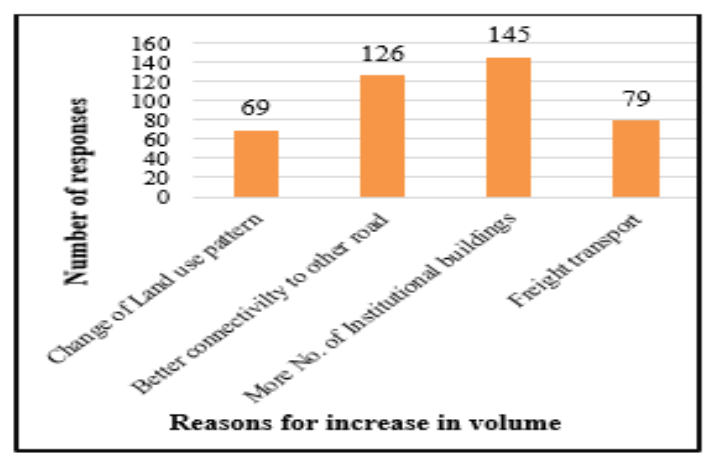

Fig. 4 Various reasons for increase in traffic volume on Mahal Road.

$>$ Out of the various reasons which were identified that contributed to the increase in traffic volume of Mahal Road, the increase in infrastructural development accounts for the highest percentage i.e., (69.7\%). Moreover, Mahal Road provides better connectivity to other local and Arterial roads which is another reason as exhibited in Fig 4.

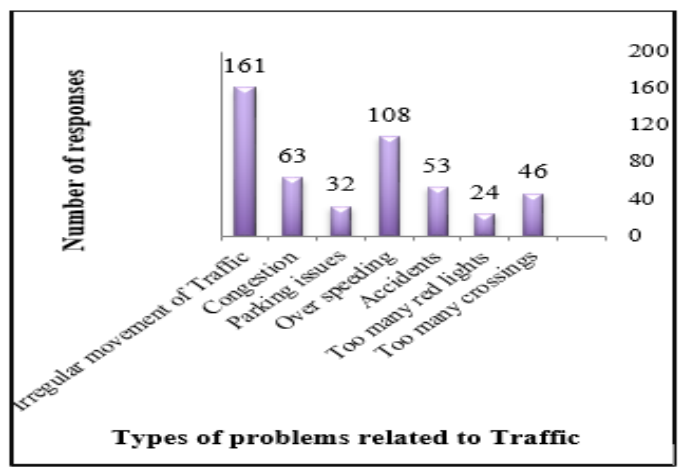

Fig. 5 Different traffic related problems faced by the people

$>\quad$ As can be seen from Fig 5, irregular movement of vehicles was the main issue which created problems in maintaining a smoother flow of traffic followed by over speeding of the vehicles which causes accidents. Due to the increase in traffic volume, congestion occurs which causes inconvenience to the road users.

$>$ Too many crossings and red-lights often disturb the flow of traffic as pointed out in the stakeholder survey depicted in Fig 5.

$>$ Moreover, to reduce the speed of vehicle, measures such as rumble strips and thermoplastic bar markings would possibly force the driver to reduce vehicular speed.

$>$ To solve the problem of congestion, channelising islands should be used which would smoothly segregate the traffic thus preventing congestion. 


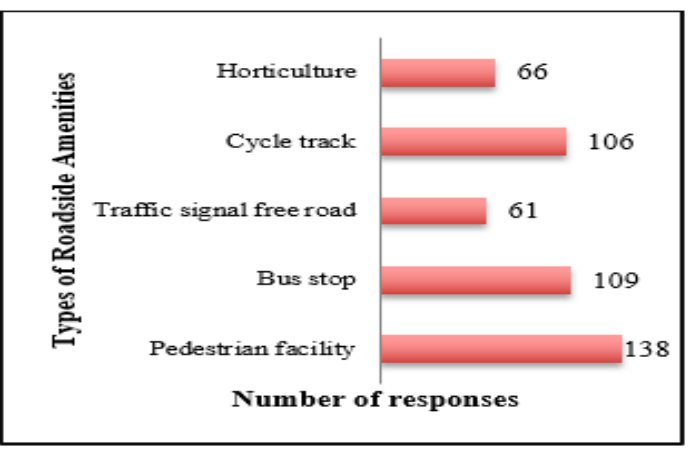

Fig. 6 Requirement of roadside amenities

$>$ Fig 6 illustrates that the majority of responses (accounting for 66\%) have expressed the need for pedestrian facilities, $52 \%$ voted for bus Stops and $51 \%$ for the cycle tracks.

$>$ Apart from that, 32\% (66 responders) and 29\% (61 responders) felt the need of 'Horticulture' and a lesser number of traffic signals on the Mahal Road respectively.

-Yes $\square$ No $\square$ Partially visible

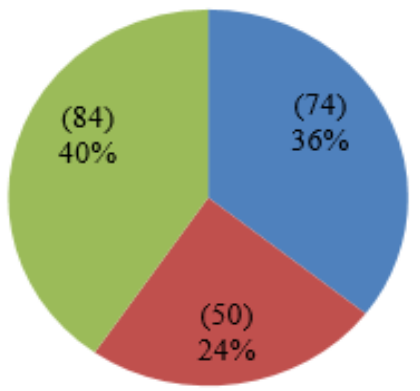

Fig. 7 Visibility of road markings/ signs

$>$ Fig 7 depicts the responses of the users regarding the visibility of road markings/ signs on the Mahal Road. $40 \%$ of the responders listed that the signs and markings were not completely visible.

$>36 \%$ of the responders mentioned that they could see the signs and markings clearly and $24 \%$ of the responders pointed out that they could not see the boards at all while using the road.

-Yes $\quad$ No $\backsim$ During peak hours only

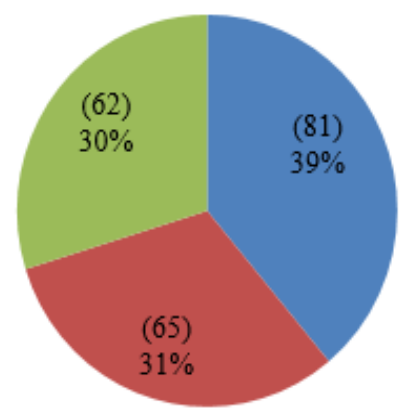

Fig. 8 Problem faced by the people when street vendors occupy the lane on main road
$>$ As indicated in figure $8,39 \%$ of the responders i.e., 81 people faced problems when street vendors occupied a lane on Mahal Road.

$>31 \%$ of the responders did not face any problem while $30 \%$ of the respondents faced difficulty when vendors engaged a lane for their purpose during peak hours only.

\section{$\because$ Yes $\square$ No}

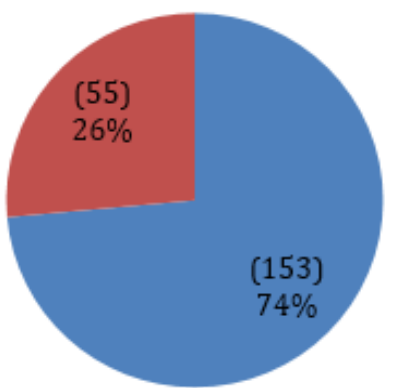

Fig. 9 Need of police enforcement

$>$ About $74 \%$ of the responders felt the need for police enforcement on Mahal Road as depicted in figure 9.

$>$ Whereas, $26 \%$ of the responders did not feel any requirement of the police enforcement.

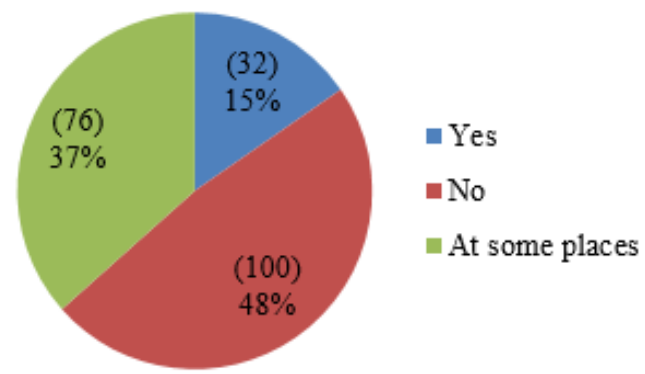

Fig. 10 Availability of emergency services on Mahal Road

$>$ Through the Stakeholder Survey, it was analysed that $48 \%$ users couldn't find proper facilities for the emergency services.

$>37 \%$ of the responders found the emergency services at some places whereas, $15 \%$ did not feel any requirement as manifested in Fig 10.

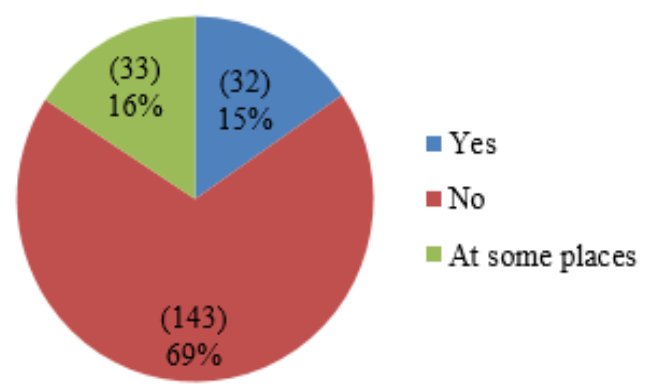

Fig. 11 Suitability for Non-motorised transport 
$>$ Out of the 208 responses, 33 people could find NMT at some places, whereas 32 people responded for complete availability of NMT.

$>$ On the basis of stakeholder survey, it was found out that Mahal Road is not properly designed for NMT. $69 \%$ of the responders could not find proper facility of NMT as explicated in Fig 11.

The above results indicate that the traffic volume has increased in the past few years and the majority of the people were not satisfied with the current condition of Mahal Road. The responses show that the facilities are required for pedestrians and NMT users in order to provide safety along with requirement of remedial measures.

\section{CONCLUSIONS \& RECOMMENDATIONS}

From the survey conducted, the various conclusions that can be drawn are as follows-

- The various reasons for the sudden increase observed in Traffic volume on Mahal Road, Jaipur from 2015 onwards includes the tremendous growth in the local and industrial market, increase in commercial space, change of land use pattern, freight transport and advancement in infrastructural development.

- Mahal road provides better connectivity to other local as well as Arterial roads and therefore people tend to travel via Mahal Road which is yet another reason for the increase in traffic volume.

- Apart from the control of increase in traffic volume, proper facilities for pedestrians and people who prefer NMT should be provided including cycle tracks.

- Implementation of traffic calming measures including Gateways and speed humps, channelising islands and installation of speed limiter on Mahal Road is required which would help in reducing the speed of vehicles giving fewer cases of road accidents.

- Due to the unavailability of parking facilities in front of shops/showrooms, people park their vehicles in an unorganised way leading to occupy larger space than needed.

- Following are the recommendations that could provide solution to the problems obtained from the survey-

- There is a need of police enforcement during the peak hour, since the majority of the people were found violating traffic signals which leads to issues like congestion, accidents etc.

- Visibility of road signs and markings is not up to the mark and an analysis is required to rectify the issue.
- Moreover, a special lane could be designed for street vendors so that they do not occupy the main lane and disturb the flow of traffic.

\section{REFERENCES}

[1] Agarwal, K. (2020) India's Population Will Be 1.52 Billion by 2036 , With $70 \%$ of Increase in Urban Areas (India's Population Will Be 1.52 billion by 2036, With $70 \%$ of Increase in Urban Areas (thewire.in) )

[2] Sood, Megha. (2020) India had most deaths in road accidents in 2019: Report (India had most deaths in road accidents in 2019: Report | Hindustan Times)

[3] Juhász, M., \& Koren, C. (2016). Getting an insight into the effects of traffic calming measures on road safety. Transportation research procedia, 14, 3811-3820.

[4] [4] India accounts for $11 \%$ of global death in road accidents: World Bank report (2021) (www.moneycontrol.com/news/ technology/auto/india-accounts-for-11-of-global-death-inroad-accidents-world-bank-report-6508191.html)

[5] FHWA (2009), Manual on Uniform Traffic Control Devices (MUTCD), Federal Highway Administration, Washington DC.

[6] Mao, J., \& Koorey, G. (2010) Investigating and modelling the effects of traffic calming devices, Proceedings of IPENZ Transportation Group Conference, Christchurch, New Zealand.

[7] Bunn, F., Collier, T., Frost, C., Ker, K., Roberts, I., \& Wentz, R. (2003). Traffic calming for the prevention of road traffic injuries: systematic review and meta-analysis. Injury prevention, 9(3), 200-204.

[8] Vaitkus, A., Čygas, D., Jasiūnienè, V., Jateikiene, L., Andriejauskas, T., Skrodenis, D., \& Ratkevičiūtė, K. (2017). Traffic calming measures: an evaluation of the effect on driving speed. Promet-Traffic\&Transportation, 29(3), 275285

[9] Indian Road Congress, IRC 99:2018-Guidelines For Traffic Calming Measures In Urban And Rural Areas (Indian Road Congress, New Delhi-2018)

[10] Damsere-Derry, J., Ebel, B. E., Mock, C. N., Afukaar, F., Donkor, P., \& Kalowole, T. O. (2019). Evaluation of the effectiveness of traffic calming measures on vehicle speeds and pedestrian injury severity in Ghana. Traffic injury prevention, 20(3), 336-342.

[11] Huang, H. F., \& Cynecki, M. J. (2000). Effects of traffic calming measures on pedestrian and motorist behaviour. Transportation Research Record, 1705(1), 26-31.

[12] Traffic Calming Measures. retrieved June 29, 2021 from Traffic Calming Measures - Institute of Transportation Engineers (ite.org)

[13] Traffic Calming. Retrieved on 15 April, 2021 from Traffic Calming: Conservation Tools

\section{NOMENCLATURE}

\begin{tabular}{|l|l|}
\hline NMT & Non-motorized transport \\
\hline GDP & Gross Domestic Product \\
\hline TCM & Traffic Calming Measures \\
\hline
\end{tabular}

